\title{
Articles
}

\section{Effect of increased plasma non-esterified fatty acids (NEFAs) on arginine-stimulated insulin secretion in obese humans}

\author{
A. Carpentier ${ }^{1}$, A. Giacca ${ }^{1,2}$, G.F. Lewis ${ }^{1}$ \\ ${ }^{1}$ Department of Medicine, Division of Endocrinology, University of Toronto, Toronto General Hospital, Toronto, Ontario, \\ Canada \\ ${ }^{2}$ Department of Physiology, University of Toronto, Toronto, Ontario, Canada
}

\section{Abstract}

Aims/hypothesis. We have shown previously that the increase of plasma non-esterified fatty acids for $48 \mathrm{~h}$ results in decreased glucose-stimulated insulin secretion in lean and non-diabetic obese subjects. It is currently not known if a prolonged increase in non-esterified fatty acids also impairs the insulin secretory response to non-glucose secretagogues.

Methods. Heparin and intralipid (to increase plasma non-esterified fatty acid concentrations by about twoto fourfold) or normal saline was infused intravenously for $48 \mathrm{~h}$ in 14 non-diabetic obese subjects. On the third day in both studies, insulin, C-peptide, proinsulin, and insulin secretion rate were assessed in response to an intravenous arginine infusion at fasting glucose concentration and a second arginine infusion after a 60 -min $11 \mathrm{mmol} / \mathrm{l}$ hyperglycaemic clamp.
Results. There were no significant differences detected in acute $(5 \mathrm{~min})$ or total $(90 \mathrm{~min})$ arginine-stimulated C-peptide or insulin secretion response in the heparin-intralipid study compared with the control group at fasting glucose or during hyperglycaemia.

Conclusion/interpretation. We have shown that a prolonged increase in plasma NEFA does not blunt arginine-stimulated insulin secretion or plasma insulin concentrations in non-diabetic obese subjects. These findings suggest that the previously demonstrated NEFA-induced impairment in insulin secretory response to glucose cannot be generalized for non-glucose secretagogues. [Diabetologia (2001) 44: 19891997]

Keywords Insulin secretion, arginine, non-esterified fatty acids, beta-cell insulin resistance, obesity.
In recent years, there has been increasing interest in the effects of NEFAs on pancreatic beta-cell function [1-5]. While it is generally accepted that the acute increase in plasma NEFAs enhances glucosestimulated insulin secretion (GSIS) [6-8], the effect

Received: 27 November 2001 and in revised form: 2 August 2001

Corresponding author: G.F. Lewis, Department of Medicine, Division of Endocrinology, University of Toronto, Toronto General Hospital, 200 Elizabeth St., Room EN 11-229, Toronto, Ontario, M5G 2C4, Canada, e-mail: gary.lewis@uhn.on.ca Abbreviations: GSIS, Glucose-stimulated insulin secretion; ISR, insulin secretion rate; $\mathrm{S}_{\mathrm{I}}$ insulin sensitivity; AIR, acute insulin response; $\mathrm{ACR}$, acute $\mathrm{C}$-peptide response; APIR, acute proinsulin response; TG, triglycerides; ANCOVA, analysis of covariance; DI, disposition index of a prolonged increase in plasma NEFA on GSIS has been more controversial. Using an intravenous infusion of heparin plus intralipid, we previously showed that an increase in plasma NEFA and triglycerides for $48 \mathrm{~h}$ in lean healthy subjects results in a loss of the stimulating effect of NEFA on GSIS [9]. Although there was no absolute reduction of GSIS below baseline at $48 \mathrm{~h}$, the beta cell was not able to fully compensate for the NEFA-induced reduction in total body insulin sensitivity $\left(\mathrm{S}_{\mathrm{I}}\right)$, a finding that we interpreted to indicate NEFA-induced impairment of beta-cell function. In contrast, others have reported an absolute increase in insulin secretion during a 48-h hyperglycaemic clamp with increases in plasma NEFAs [10] but they did not assess insulin secretion in relation to the NEFA-induced reduction in $\mathrm{S}_{\mathrm{I}}$. 
Table 1. Characteristics of the study participants

\begin{tabular}{|c|c|c|c|c|c|c|}
\hline & Age (year) & Sex & $\mathrm{BMI}^{\mathrm{a}}\left(\mathrm{kg} / \mathrm{m}^{2}\right)$ & $\begin{array}{l}\text { Fasting plasma } \\
\text { glucose }(\mathrm{mmol} / \mathrm{l})\end{array}$ & $\begin{array}{l}\text { Fasting plasma } \\
\text { insulin (pmol/l) }\end{array}$ & $\begin{array}{l}\text { Fasting plasma } \\
\mathrm{TG}^{\mathrm{b}}(\mathrm{mmol} / \mathrm{l})\end{array}$ \\
\hline 1 & 39 & M & 43.4 & 4.4 & 99 & 2.41 \\
\hline 2 & 42 & M & 32.9 & 5.5 & 131 & 1.36 \\
\hline 4 & 49 & $\mathrm{~F}$ & 33.2 & 5.6 & 63 & 1.36 \\
\hline 5 & 52 & $\mathrm{~F}$ & 27.6 & 4.8 & 37 & 2.35 \\
\hline 6 & 42 & M & 33.2 & 6.2 & 145 & 3.19 \\
\hline 9 & 37 & $\mathrm{~F}$ & 31.3 & 4.6 & 114 & 1.40 \\
\hline 10 & 56 & $\mathrm{~F}$ & 28.6 & 5.1 & 27 & 1.36 \\
\hline 11 & 58 & M & 33.6 & 6.3 & 69 & 1.98 \\
\hline 12 & 36 & $\mathrm{~F}$ & 32.8 & 5.1 & 39 & 0.78 \\
\hline 13 & 60 & M & 30.1 & 5.9 & 48 & 1.68 \\
\hline 14 & 49 & $\mathrm{~F}$ & 38.5 & 5.2 & 67 & 2.45 \\
\hline
\end{tabular}

${ }^{a}$ BMI

b $\mathrm{TG}$, triglycerides

Recently, we reported that obese non-diabetic subjects but not obese subjects with Type II (non-insulin-dependent) diabetes mellitus showed an absolute reduction in GSIS after a $48 \mathrm{~h}$ increase in plasma NEFAs and triglycerides [11]. Our results supported the findings which have shown a decrease in first phase insulin response to glucose with a prolonged increase in plasma NEFAs in healthy subjects [12] and improvement of first phase insulin response with 1week lowering of plasma NEFAs with acipimox in normoglycaemic relatives of patients with Type II diabetes [13].

In non-obese patients with Type II diabetes, the insulin secretory response to arginine seems to be well preserved, as opposed to the poor insulin secretory response to glucose seen in these patients [14]. In vitro studies have shown that NEFAs acutely enhance both GSIS and non-glucose-stimulated insulin secretion [15]. In contrast, in vitro studies have suggested that the impairment of beta-cell insulin secretion mediated by prolonged exposure to NEFA could be specific for GSIS [16-19]. To our knowledge, however, this has never been assessed in vivo in humans. We therefore examined the effect of prolonged increase of plasma NEFA on the beta-cell response to a nonglucose insulin secretagogue, arginine, and we assessed the effect on glucose potentiation of argininestimulated insulin secretion. To that aim, we measured the acute incremental insulin, C-peptide and insulin secretion response as well as the total incremental area under the respective curves of these parameters after arginine stimulation at both fasting and at about $11 \mathrm{mmol}$ of plasma glucose. We chose to study obese non-diabetic humans since we had previously shown that these subjects are particularly sensitive to the impairing effect of chronically increased NEFAs on beta-cell function [11]. Arginine is thought to stimulate insulin secretion mainly by inducing pancreatic beta-cell membrane depolarization by directly entering the cell through cationic amino acid transporters [20-23], and therefore, arginine-induced insulin secretion bypasses the $\mathrm{K}^{+}$-ATP channels, which mediate a large part of the glucose-stimulated insulin secretion. Thus, examining the NEFA-mediated effect on arginine-stimulated insulin secretion could shed more light on the potential mechanisms of the beta-cell dysfunction associated with prolonged increase of plasma NEFAs.

\section{Subjects and methods}

Subjects. Fourteen non-diabetic obese research volunteers ( 5 men and 9 women) participated in the study. Their demographic and clinical characteristics are shown in Table 1. Diabetes mellitus was excluded by assessing fasting plasma glucose concentrations on at least two occasions. None of the participants had systemic illness other than controlled high blood pressure and mild hyperlipidaemia. The dose of anti-hypertensive medications remained the same throughout the study and no patient was taking any lipid lowering agent. None of the subjects were treated with $\beta$-blockers or any other agent known to affect islet autonomic function. The pre-menopausal women were studied during the follicular phase of their menstrual cycle on both occasions. Informed written consent was obtained from all participants in accordance with the guidelines of the Human Subjects Review Committee of the University Health Network, Toronto.

Experimental protocols. The participants were studied on two occasions, 4 to 6 weeks apart and each served as his or her own control. Subjects were admitted to the Metabolic Investigation Unit of the Toronto General Hospital, where they received a control diet and a continuous infusion of intralipid and heparin to increase plasma NEFA concentrations for $48 \mathrm{~h}$ or a control saline infusion before and during the assessment of pancreatic insulin secretion. After a 12-h overnight fast, an 
intravenous catheter was placed in each forearm, one for infusion and one for blood sampling. The arm containing the sampling catheter inserted in a distal vein was maintained in a heating blanket $\left(\sim 65^{\circ} \mathrm{C}\right)$ to arterialize venous blood. After a fasting baseline blood sample was drawn, heparin sodium (Organon Teknika, Toronto, Canada) and intralipid $20 \%$ solution (Baxter, Mississauga, Canada) were infused at 250U/h and $40 \mathrm{ml} / \mathrm{h}$ respectively, starting at 0800 hours and continued for $48 \mathrm{~h}$ before and then during the subsequent testing of insulin secretion. Intralipid is a sterile fat emulsion containing $20 \%$ soybean oil, $1.2 \%$ egg phospholipids, and $2.25 \%$ glycerin in water. During this time subjects consumed an isocaloric diet consisting of $20 \%$ calories derived from protein, $30 \%$ from fat, and $50 \%$ from carbohydrate, divided into three meals and one evening snack. Blood samples were drawn at approximately 0800 hours (after a 12-h overnight fast) and 1600 hours on day one and two for glucose, insulin, NEFA and triglycerides.

The experimental protocol is shown in Figure 1. At approximately 0800 hours on day three after a 12 -h overnight fast, with the heparin-intralipid or saline infusion continuing at a steady rate until the end of the study, blood samples were drawn at $10 \mathrm{~min}$ intervals for glucose, insulin, and C-peptide, during a $30 \mathrm{~min}$ basal period, before the arginine infusion. Baseline samples for plasma NEFA, proinsulin, and triglycerides were also drawn at time -30 and 0 . Samples for NEFA and triglyceride analysis were collected into chilled EDTA tubes on ice containing $30 \mu \mathrm{g} / \mathrm{ml}$ blood of the lipase inhibitor orlistat (tetrahydrolipstatin, Hoffman La Roche, Mississauga, Ontario, Canada), to prevent ongoing in vitro lipolysis of the samples [24]. The subjects then underwent an arginine stimulation test, first at fasting plasma glucose and subsequently during a hyperglycaemic clamp. The arginine prime and infusion modality has been used by others previously [25] and results in a biphasic insulin secretory response at each arginine bolus and infusion period. Briefly, a $5 \mathrm{~g}$ intravenous bolus of L-arginine hydrochloride (Sabex, Boucherville, Canada - 4:1 vol:vol with $\mathrm{NaHCO}_{3}$ ) was infused over $45 \mathrm{~s}$ followed by $25 \mathrm{~g}$ infused over $30 \mathrm{~min}$ at time $0 \mathrm{~min}$. At time $90 \mathrm{~min}$, a variable $20 \% \mathrm{dex}$ trose infusion was started and was adjusted according to plasma glucose measured every 5 min to maintain plasma glucose at about $11 \mathrm{mmol} / \mathrm{l}$. At time $150 \mathrm{~min}$, a second arginine infusion identical to the first one was administered while maintaining hyperglycaemia with the dextrose infusion for the remainder of the study. Since it is technically difficult to clamp blood glucose in the first 15 min following the acute administration of arginine, the dextrose infusion was kept constant for $15 \mathrm{~min}$ after the arginine bolus to avoid any alteration induced by investigators of the acute beta-cell response between the two studies. However, the glucose infusion was adjusted according to the change in glucose concentration after $15 \mathrm{~min}$. Blood samples to measure plasma glucose, insulin, and C-peptide were drawn at $0,2,3,5,7,10,20,30,40,50,60,70,80$, 90 min, NEFA and TG were measured at $0,30,60$, and $90 \mathrm{~min}$, and proinsulin concentrations were measured at 0,2 , $3,5,80$, and 90 min after the beginning of both arginine infusions.

Laboratory methods. Glucose was assayed enzymatically at the bedside using a Beckman Glucose Analyser II (Beckman Instruments, Fullerton, Calif., USA). Insulin was measured by radioimmunoassay using a double antibody separation method (Pharmacia Diagnostic, Uppsala, Sweden) with an intra-assay and interassay coefficient of variation of $5.8 \%$ and $11.2 \%$, respectively. There is a $41 \%$ cross-reactivity with proinsulin reported in this assay. C-peptide was measured by a double antibody C-peptide radioimmunoassay (Diagnostic Products, Los Angeles, Calif., USA). The intra-assay and interassay coeffi- cient of variation for this assay is $4.1 \%$ and $15.1 \%$ respectively. Proinsulin was measured using a Linco human proinsulin RIA kit (CV 3.2\%). The samples for both studies in the same patient were assayed simultaneously with the same kit for insulin, proinsulin, and C-peptide. Non-esterified fatty acids were measured by a colorimetric method (Wako Industrials, Osaka, Japan). Triglycerides were measured as esterified glycerol using an enzymatic colorimetric kit (Boehringer Mannheim Diagnostica). Free glycerol was eliminated from the sample in a preliminary reaction followed by enzymatic hydrolysis of triglyceride with subsequent measurement of the liberated glycerol by colorimetry.

Estimation of ISR. Pancreatic insulin secretion rate was calculated from peripheral plasma C-peptide concentrations by deconvolution using a two compartment mathematical model with standard parameters for C-peptide distribution and metabolism [26] (The software program for calculation of insulin secretion was kindly provided by Drs. K. Polonsky and J. Sturis, University of Chicago, Chicago, Ill., USA). Although the determination of individual C-peptide kinetic parameters would have been ideal, unfortunately C-peptide was no longer commercially available for in vivo use in humans at the time these studies were carried out. The use of standard parameters for C-peptide clearance and distribution has been shown to result in insulin secretion rates which differ in each subject by only 10 to $12 \%$ from those obtained with individual parameters and there is no systematic overestimation or underestimation of insulin secretion [26]. These parameters were validated for both obese non-diabetic and diabetic subjects in addition to normal control subjects. The same protocol of a previous study was used without individual C-peptide boluses [27]. Further, our studies were done on the same individuals and the comparisons were within subjects. To our knowledge, there is no evidence that differences in plasma NEFA concentrations or intralipid and heparin infusion affect the kinetics of C-peptide in humans.

Assessment of the beta-cell response to arginine. The acute insulin, C-peptide, and proinsulin response (AIR, ACR, and APIR respectively) was measured by calculating the mean increase over baseline of insulin, C-peptide, and proinsulin, respectively, at time 2, 3, and 5 min after the arginine bolus at both fasting plasma glucose and hyperglycaemia. The total incremental area under the curve of C-peptide, insulin and ISR from time 0 to $90 \mathrm{~min}$ after the arginine bolus was also calculated both at fasting plasma glucose and during hyperglycaemia using the trapezoidal rule.

Assessment of glucose potentiation of the acute arginine response. For each subject, the calculated AIR, ACR, and APIR were plotted against the plasma glucose at fasting and during hyperglycaemia. The slope connecting the two points for each of these three variables was then assessed for all the subjects. These slopes represent the glucose potentiating effect of insulin, C-peptide, and proinsulin response to arginine respectively [25].

Statistical analysis. The data were expressed as means \pm standard error (SEM). The comparison of the mean glucose, NEFA, TG, insulin, C-peptide, and proinsulin concentrations during the steady-state periods (time -30 to $0 \mathrm{~min}$, and time 130 to $150 \mathrm{~min}$ ) and Ginf, $\mathrm{S}_{\mathrm{I}}$, and ISR at steady state period (time 130 to $150 \mathrm{~min}$ ) between control and 48-h heparin-intralipid study were assessed by two-tailed paired $t$ tests. The AIR, ACR, APIR, total incremental AUC of glucose, insulin, $\mathrm{C}$-peptide, and ISR in response to arginine at fasting glucose 


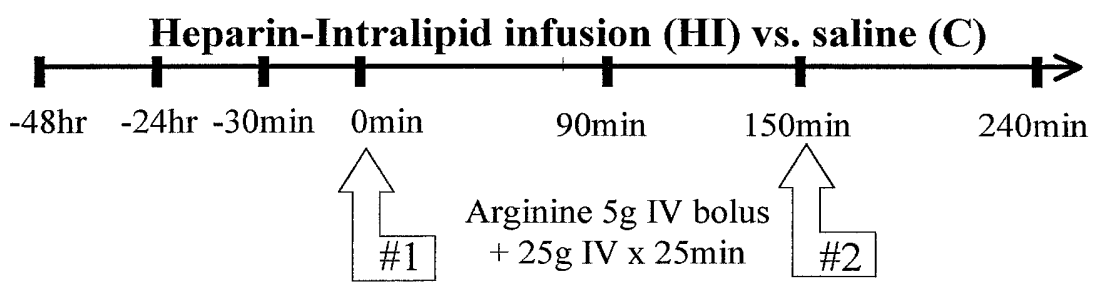

Fig. 1. Experimental protocol. All subjects received a controlled diet until $12 \mathrm{~h}$ before the baseline sampling period $(-30 \mathrm{~min})$

concentration and during hyperglycaemia were also compared using two-tailed paired $t$ tests. However, glucose concentrations were slightly higher in the 48-h heparin-intralipid study throughout the baseline and first arginine infusion periods, because the glucose was not clamped during these periods. To account for this, the acute $(5 \mathrm{~min})$ and total $(90 \mathrm{~min})$ incremental responses of insulin, C-peptide, and ISR after the first arginine infusion were also compared after adjustment for mean baseline glucose concentration using ANCOVA. A $p$ value of less than 0.05 was considered statistically significant. All the statistical analyses were done using the SAS statistical software version 8.0 (Cary, N.C., USA).

\section{Results}

The glucose, insulin, NEFA and triglyceride concentration measured at $0800 \mathrm{~h}$ and $1600 \mathrm{~h}$ on days one and two, and at $800 \mathrm{~h}$ on day three of the 48-h heparin-intralipid and control study are given in Table 2 . After starting the heparin-intralipid infusion, NEFA were maintained in a high physiological range for the entire study. Plasma NEFA were significantly higher $(p<0.05)$ by design in the heparin-intralipid infusion compared with the control study at all times after the start of the heparin and intralipid infusion and were increased about twofold at fasting on the morning of the intravenous arginine infusions. Tri-
D20\% IV infusion to maintain plasma glucose at $\sim 11 \mathrm{mmol} / 1$

glyceride concentrations also rose significantly with the heparin and intralipid infusion $(p<0.05)$ on day one and day two compared with the control study and reached about a twofold increase on day three $(p<0.05)$. The fasting plasma glucose concentration was slightly but not significantly higher after a 48-h infusion of heparin-intralipid compared with the saline infusion. The fasting proinsulin concentrations were similar in both studies $(14.2 \pm 3.8$ vs. $11.8 \pm 2.3$ $\mathrm{pmol} / \mathrm{l}$ in the 48-h heparin-intralipid study and control study, respectively, $p=\mathrm{NS}$ ).

Arginine stimulation at fasting plasma glucose (time 0 to $90 \mathrm{~min}$ ). After the first arginine bolus, glucose concentrations rose slightly in both studies and returned slowly toward fasting concentrations before the start of the dextrose infusion, at $90 \mathrm{~min}$ (Fig.2A). The mean glucose concentration between 70 and $90 \mathrm{~min}$ was slightly higher in the 48-h heparin-intralipid study compared with the control study $(5.8 \pm 0.1$ vs $5.5 \pm 0.1 \mathrm{mmol} / 1, p<0.01)$. The NEFA concentrations (Fig. 2b) declined in both studies from the baseline but remained significantly higher in the former $(p<0.01)$. The TG concentrations (Fig. 2C) remained stable and tended to be higher in the heparin-intralipid study $(p=0.05)$.

After the first arginine bolus, the increase in plasma insulin (Fig. 2D) was greater in the 48-h heparinintralipid study compared with the control study (total incremental AUC between 0-90 min: $13909 \pm$ 2549 vs $8723 \pm 1092 \mathrm{pmol} / 1.90 \mathrm{~min}$ respectively, $p=0.01)$ but the AIR (0-5 min) (Fig. 4A) was similar

Table 2. Fasting plasma glucose, insulin, NEFA, and triglyceride concentrations for $48 \mathrm{~h}$ before the graded intravenous glucose infusion (day 3)

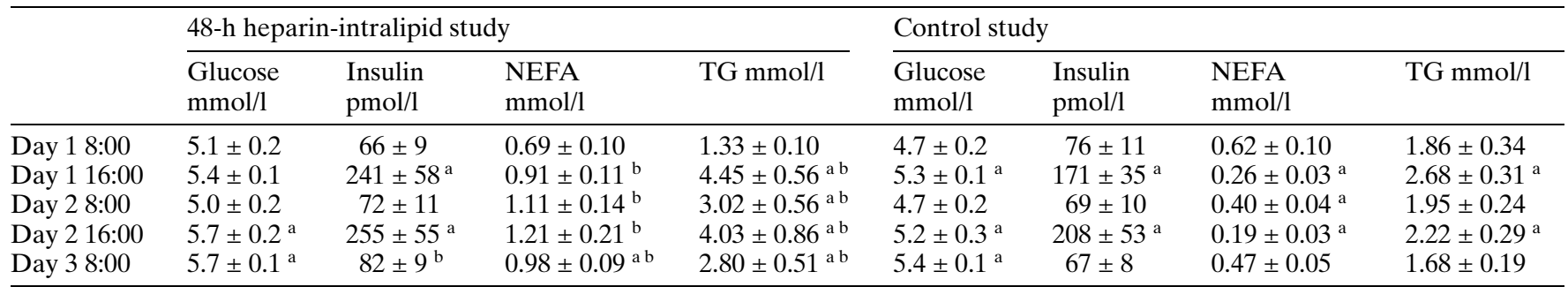

Measurements at 0800 hours were done after a 12-h overnight fast, whereas samples taken at 1600 hours were not done in the fasting state
Data are means \pm SEM

${ }^{\mathrm{a}} p<0.05$ vs day 1,0800 values

${ }^{\mathrm{b}} p<0.05$ vs control study 

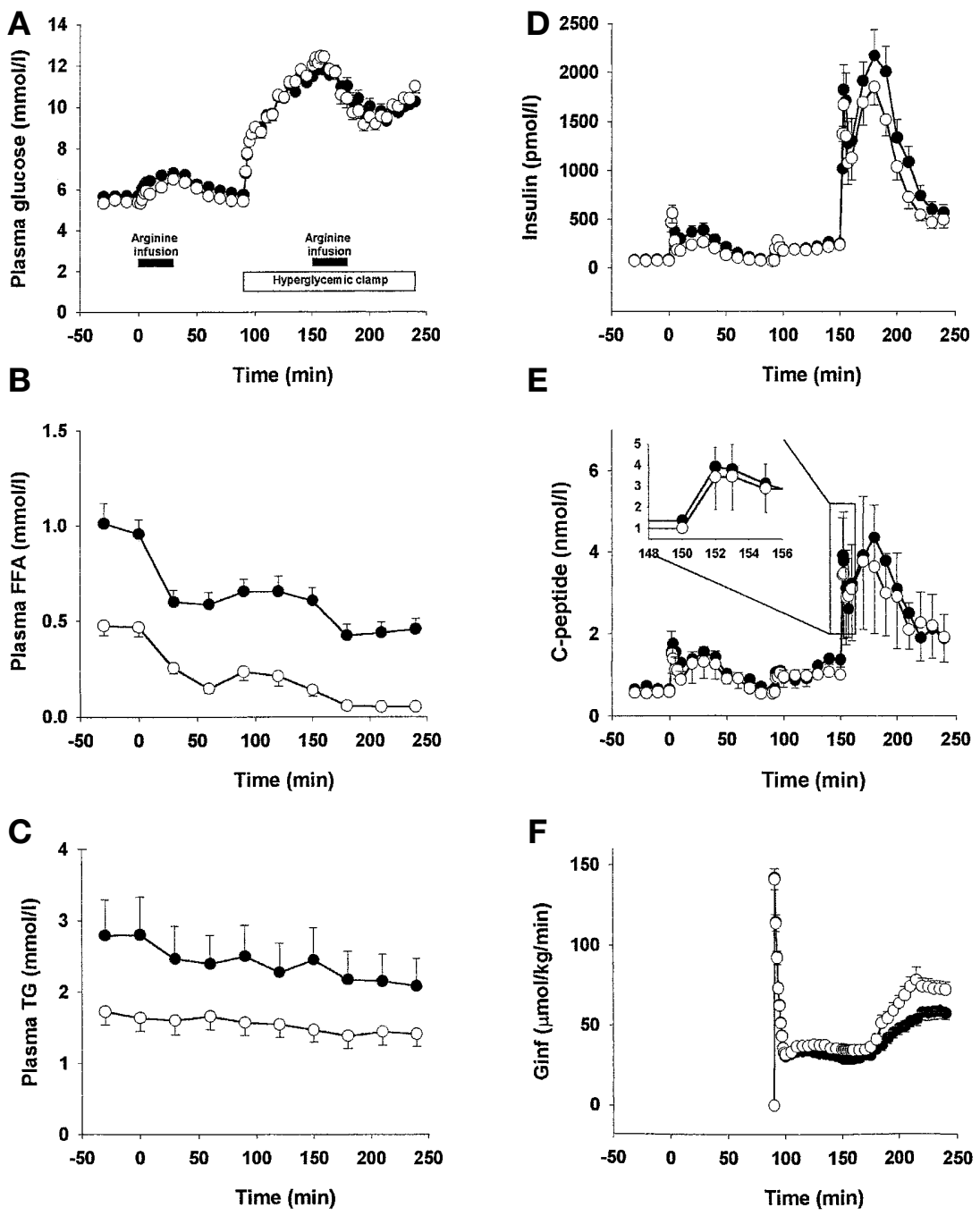

Fig. 2. Mean profiles of $\mathbf{A}$ glucose, B NEFA (non-esterified fatty acids), $\mathbf{C}$ triglycerides, $\mathbf{D}$ insulin, $\mathbf{E}$ C-peptide, and $\mathbf{F}$ Ginf (glucose infusion rate) vs time during intravenous arginine stimulation at fasting plasma glucose concentration and during hyperglycaemia in non-diabetic obese subjects $(n=14)$. These figures illustrate profiles following $48 \mathrm{~h}$ of either a heparin-intralipid infusion (closed circles) or a saline infusion (open circles). In the heparin-intralipid study the infusion of heparin and intralipid was continued throughout the experiment. The baseline period is time -30 to $0 \mathrm{~min}$. The arginine stimulation at fasting glucose concentration refers to the time period 0 to $90 \mathrm{~min}$. Dextrose infusion was started at time 90 min and adjusted to maintain plasma glucose concentration at approximately $11 \mathrm{mmol} / \mathrm{l}$. The steady state clamp period refers to time 130 to $150 \mathrm{~min}$. The arginine stimulation during hyperglycaemia refers to the time period 150 to $240 \mathrm{~min}$. The insert in panel (E) depicts the ACR at hyperglycaemia in both studies

in both studies $(380 \pm 71$ vs $367 \pm 72 \mathrm{pmol} / \mathrm{l}$, respectively, $p=\mathrm{NS})$. The 0 to $90 \mathrm{~min}$ incremental C-peptide AUC (Fig. 2E) was also similar in the 48-h heparin-intralipid compared with the control study $(42.34 \pm 26.14$ vs $35.96 \pm 11.53 \mathrm{nmol} / 1.90 \mathrm{~min}$, respectively, $p=\mathrm{NS}$ ). The ACR (Fig. 4B) was not different

$(0.96 \pm 0.48$ vs $0.78 \pm 0.38 \mathrm{nmol} / \mathrm{l}, \quad$ respectively, $p=\mathrm{NS}$ ), a conclusion that was not altered by adjustment for the mean baseline glucose concentration $(p=\mathrm{NS})$. The APIR was also similar between the two studies $(10.5 \pm 1.9$ vs $7.6 \pm 1.7 \mathrm{pmol} / \mathrm{l}$, respectively, $p=\mathrm{NS}$ ) (Fig. 4C). Adjustment for the mean baseline glucose concentration did not change this conclu$\operatorname{sion}(p=\mathrm{NS})$.

The basal ISR (Fig.3) was similar between the 48-h heparin-intralipid study and the control study $(183 \pm 30$ vs $161 \pm 36 \mathrm{pmol} / \mathrm{min}$, respectively, $p=$ NS). The incremental ISR AUC after the first arginine bolus was not different in the 48-h heparinintralipid study compared with the control study $(13580 \pm 6680$ vs $11462 \pm 3954$ pmol respectively, $p=$ NS).

Hyperglycemic clamp period prior to second arginine stimulation (time 90 to $150 \mathrm{~min}$ ). The mean glucose concentrations in the hyperglycaemic clamp (Fig. 2A) increased progressively to approximately $11 \mathrm{mmol} / \mathrm{l}$ between time 130 and $150 \mathrm{~min}$ in both studies. During this period (130-150 min), NEFA concentrations (Fig.2B) were again significantly 


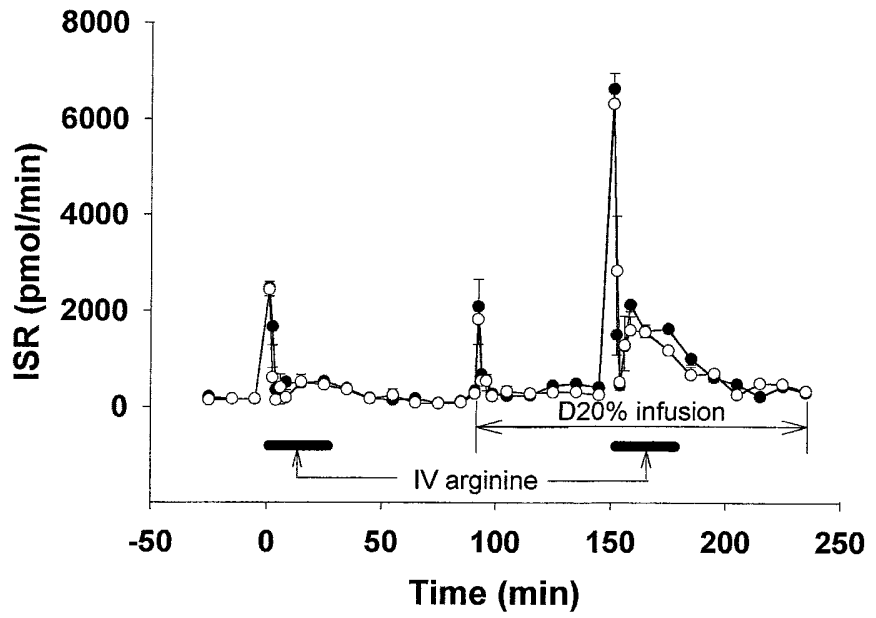

Fig.3. Insulin secretion rate (ISR) throughout the arginine stimulation on day 3

higher in the 48-h heparin-intralipid study than in the control study $(p<0.01)$.

Insulin (Fig.2D) and C-peptide concentrations (Fig.2E) increased to a similar steady concentration in both studies between time 130 and $150 \mathrm{~min}$. The proinsulin concentrations were also not different between the two studies $(35.2 \pm 6.8 \mathrm{vs} .28 .7 \pm 4.9 \mathrm{pmol} / \mathrm{l}$ in the 48-h heparin-Intralipid vs control study, $p=\mathrm{NS})$.

Between times 130 and 150 min, Ginf (Fig.2F) was similar between the 48-h heparin-intralipid and the control study $(31.3 \pm 2.0$ vs. $36.4 \pm 3.0 \mu \mathrm{mol}$. $\mathrm{kg}^{-1} \cdot \mathrm{min}^{-1}$ respectively, $\left.p=\mathrm{NS}\right)$. During this period, the ISR (Fig. 3) was also similar between the two studies.

Arginine stimulation test at hyperglycaemia (time 150 to $240 \mathrm{~min}$ ). After the second arginine bolus, the glucose total AUC (Fig. 2A) was similar in the heparinintralipid and in the control studies. The mean plasma glucose concentration was also similar in both studies throughout that period. Plasma NEFA (Fig. 2B) further declined in both studies during this period to reach a nadir at the end of the study, but remained significantly higher in the 48-h heparin-intralipid compared with the control study $(p<0.01)$. The plasma TG concentrations (Fig. 2C) tended to be higher in the 48-h heparin-intralipid study than in the control study but the difference was not significant $(p=0.06)$.

The total insulin incremental AUC (Fig.2D) after the arginine bolus during hyperglycaemia (between time 150-240 min) was higher in the 48-h heparinintralipid study than in the control study $(99506 \pm 10631$ vs $79477 \pm 9243 \mathrm{pmol} / 1.90 \mathrm{~min} \mathrm{re}-$ spectively, $p=0.04)$. The AIR $(150-155 \mathrm{~min})$ (Fig. 4A), however, was similar between the two studies $(1328 \pm 200$ vs $1275 \pm 198 \mathrm{pmol} / \mathrm{l}$ respectively, $p=\mathrm{NS}$ ). The total C-peptide (Fig.2E) incremental

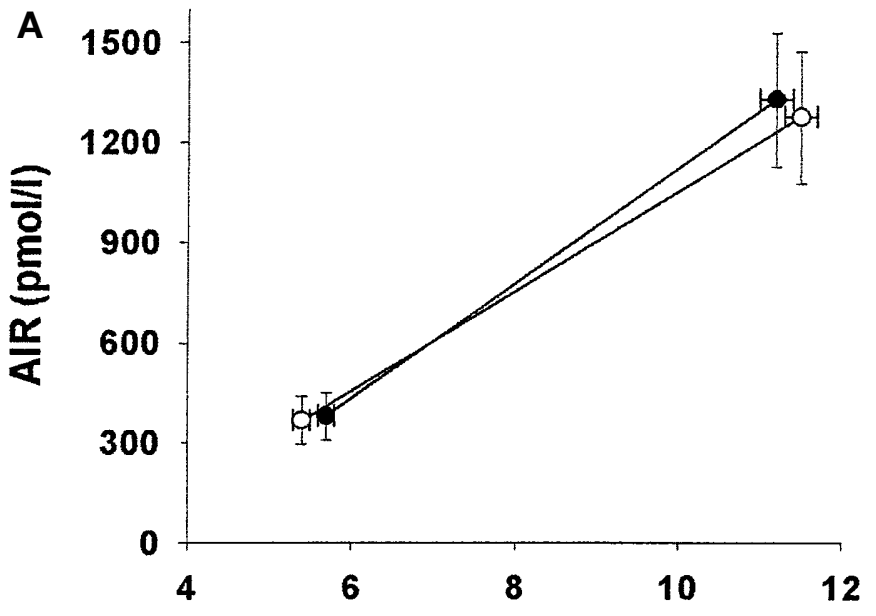

B
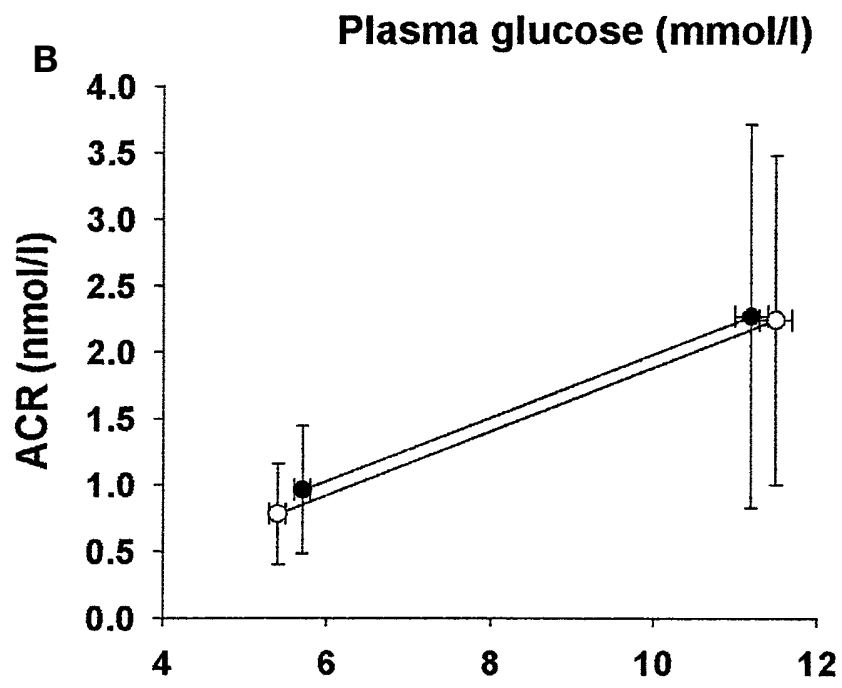

Plasma glucose ( $\mathrm{mmol} / \mathrm{l})$

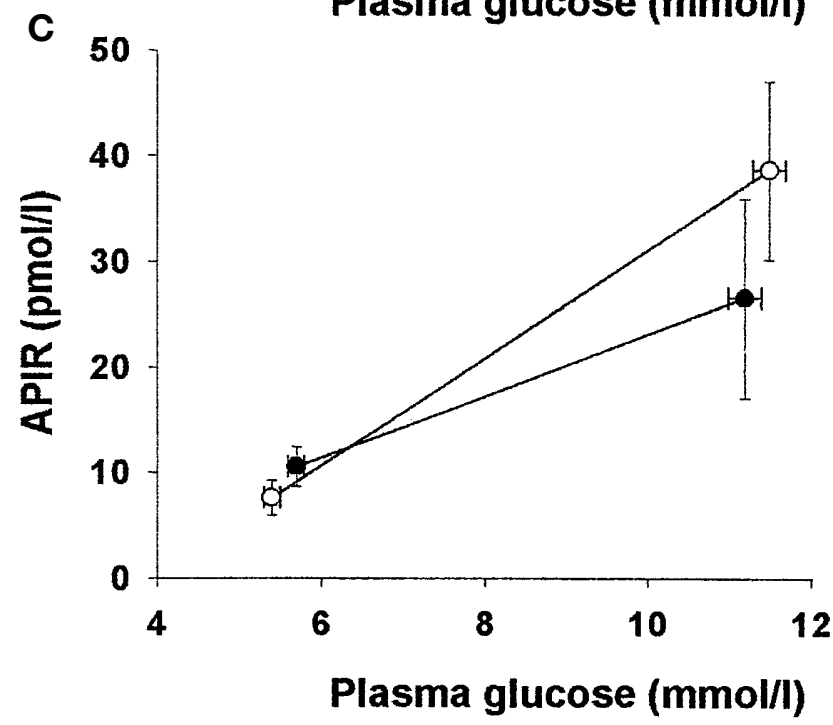

Fig. 4. Relation between the mean acute insulin response (AIR) (A), acute C-peptide response (ACR) (B), and acute proinsulin response (APIR) $(\mathbf{C})$ to arginine respectively, vs mean plasma glucose concentration in non-diabetic obese subjects $(n=14)$ after $48 \mathrm{~h}$ of either a heparin-intralipid infusion (closed circles) or a saline infusion (open circles). The slope of this linear relation represents the glucose potentiation of AIR, $\mathrm{ACR}$, and APIR to arginine respectively. Data $=$ means $\pm \mathrm{SEM}$ 
AUC was not different between the two studies $(153.2 \pm 85.3$ vs $160.6 \pm 80.1 \mathrm{nmol} / 1.90 \mathrm{~min}$ in the 48-h heparin-intralipid study vs control study respectively, $p=\mathrm{NS}$ ). The ACR (Fig. 4B) was also similar in the 48-h heparin-intralipid study compared with the control study $(2.27 \pm 1.44$ vs. $2.24 \pm 1.24 \mathrm{nmol} / 1$ respectively, $p=\mathrm{NS}$ ). The APIR (acute proinsulin response) (Fig. 4C) following the intravenous bolus of arginine, however, tended to be blunted during hyperglycaemia in the 48-h heparin-intralipid study compared with the control study $(26.5 \pm 9.4$ vs $38.6 \pm 8.4 \mathrm{pmol} / \mathrm{l}$ respectively, $p=0.06$ ).

The total incremental ISR AUC (Fig. 3) after the second arginine bolus did not differ in the 48-h heparin-intralipid study compared with the control study $(44227 \pm 22830$ vs $50939 \pm 23351$ pmol respectively, $p=0.07)$. The total glucose infusion required after the second arginine bolus $(4.02 \pm 0.26$ vs $5.16 \pm$ $0.36 \mathrm{mmol} / \mathrm{kg}$ respectively, $p<0.01)$ as well as the Ginf, at steady-state during the last $20 \mathrm{~min}$ of the study (time 220 to $240 \mathrm{~min})(58.1 \pm 4.6$ vs. $73.1 \pm 5.1$ $\mu 16 \mathrm{~mol} \cdot \mathrm{kg}^{-1} \cdot \mathrm{min}^{-1}$ respectively, $\left.p<0.01\right)$ were lower in the $48 \mathrm{~h}$ heparin-intralipid study compared with the control study (Fig. 2F).

Glucose potentiation of the beta-cell response to arginine. The relation between AIR (A), ACR (B), and APIR (C) respectively, and plasma glucose concentrations in both the 48-h heparin-intralipid study and the control study are shown in Figure 4. The slope (arbitrary units) of the lines joining the two points represents the glucose potentiation of arginine stimulation of the insulin, C-peptide, and proinsulin response. There was a marked glucose potentiation of AIR which was similar in the two studies $(177 \pm 29$ vs $154 \pm 28$ in 48-h heparin-intralipid compared with the control study respectively, $p=\mathrm{NS}$ ). The glucose potentiation of ACR was also similar in the 48-h heparin-intralipid study compared with the control $(0.20 \pm 0.16$ vs. $0.24 \pm 0.14$ respectively, $p=$ NS). The glucose potentiation of APIR, however, tended to be lower in the heparin-intralipid study than in the control study $(2.40 \pm 1.91$ vs $5.23 \pm 1.22$ respectively, $p=0.07)$.

\section{Discussion}

We have shown that a prolonged infusion of heparin and intralipid for $48 \mathrm{~h}$, which resulted in a two- to fourfold increase of fasting plasma NEFA, was not associated with an absolute reduction of the acute (5 min) or 90-min C-peptide or insulin secretion response to intravenous arginine infusion either at normoglycaemia or during hyperglycaemia. These observations contrast with our previous finding of a reduction of GSIS after a prolonged increase of plasma NEFA in a similar population [11]. Our present findings also contrast with previous findings of others whom have shown blunting of the acute insulin response to glucose after a 24-h increase of plasma NEFAs in healthy non-obese subjects [12]. Furthermore, our results suggest that glucose potentiation of the acute insulin secretory response to arginine is not altered by a 48-h increase of plasma NEFA, in keeping with the findings of previous in vitro studies that have suggested that the impairment of beta-cell insulin secretion mediated by prolonged exposure to NEFA could be specific for glucose [16-19].

The only significant difference noted between the heparin-intralipid studies and the control studies, both at fasting plasma glucose as well as at hyperglycaemia, was a higher incremental insulin AUC. No such differences in the $\mathrm{C}$-peptide or calculated insulin secretion rate AUC were noted. The most likely explanation for this finding is a NEFA-mediated reduction of insulin extraction by the liver [28]. Although insulin extraction by the liver seems to be constant throughout the physiological range of insulin concentration at steady state insulin concentrations [29, 30], it declines during dynamic (non steady state) conditions and in the presence of very high insulin concentrations, similar to those seen in our study during the second bolus infusion of arginine [31-33].

The total glucose infusion required to maintain similar plasma glucose concentrations during the heparin-intralipid infusion was significantly lower than in the saline study, suggesting that prolonged increases of plasma NEFA led to a reduction in insulin sensitivity in our present study. Cross-sectional [34] and longitudinal studies in humans [35] and in experimental studies in animals $[36,37]$ have shown that a reduction in insulin sensitivity is usually associated with a compensatory increase in insulin secretion to maintain glucose homeostasis. This observation has led to the concept of "disposition index" of insulin (DI), which implies that the product of insulin secretion and insulin sensitivity should remain constant for a given population (or individual) if glucose homeostasis is to remain unaltered $[38,39]$. In healthy non-obese subjects, we have previously shown that this compensatory insulin secretion increase occurs after a short period of plasma NEFA increase but is lost after a 48-h infusion of heparin and intralipid [9]. Unfortunately, the absence of a steady state insulin concentration after the second arginine bolus precludes the accurate measurement of insulin sensitivity during this period in our present study.

The subjects who participated in the present as well as in our previous study [11] were heterogeneous with regards to glucose tolerance, although none had definite Type II diabetes. The small number of subjects in our present study does not allow us to compare the effect of prolonged increases of plasma NEFA on arginine-stimulated insulin secretion between the obese subjects with and without glucose intolerance and therefore we could not determine if the 
glucose tolerance status modulates this response in this population.

There are several implications of our findings for the pathophysiological role of chronically increased plasma NEFA in beta-cell dysfunction. First, we did not show an absolute NEFA-mediated reduction in insulin secretion in acute response to arginine, as we have previously shown for GSIS [11]. Because arginine is believed to stimulate insulin secretion distal in the insulin secretion cascade of events, primarily by inducing depolarisation of the beta-cell membrane $(22,23,40)$, the absence of a significant effect at normoglycaemia, combined with our previous observation of a NEFA-induced reduction of GSIS, would suggest that prolonged NEFA exposure could alter glucose-mediated insulin secretion and glucose potentiation of arginine-stimulated insulin secretion primarily by interfering with the metabolism of glucose, leaving the exocytotic machinery relatively intact. The stimulatory effect of arginine on acute insulin secretion at hyperglycaemia and glucose potentiation were also not affected in our present study, which suggest an absence of interaction between glucose and a prolonged increase of plasma NEFA on arginine-stimulated acute insulin secretion.

In conclusion, we have shown in non-diabetic obese subjects that a prolonged increase of plasma NEFA does not blunt arginine-stimulated insulin secretion or plasma insulin concentrations. These findings suggest that the previously shown NEFA-induced impairment in insulin secretory response to glucose cannot be generalized for non-glucose secretagogues.

Acknowledgements. This work was funded by a Research Grant from the Canadian Diabetes Association. Dr. Carpentier was supported by a Medical Research Council, Heart and Stroke Foundation of Canada fellowship and is now a new investigator of the Canadian Institutes of Health Research. Dr. Lewis is a Canada Research Chair in Diabetes and a Career Investigator of the Heart and Stroke Foundation of Canada.

\section{References}

1. Unger RH (1995) Lipotoxicity in the pathogenesis of obesity-dependent NIDDM. Genetic and clinical implications. Diabetes 44: 863-870

2. Prentki M, Corkey BE (1996) Are the beta-cell signalling molecules malonyl-CoA and cytosolic long-chain acylCoA implicated in multiple tissue defects of obesity and NIDDM? Diabetes 45: 273-283

3. Boden G (1997) Role of fatty acids in the pathogenesis of insulin resistance and NIDDM. Diabetes, 46: 3-10

4. Björklund A, Yaney G, McGarry JD, Weir G (1997) Fatty acids and beta-cell function. Diabetologia 40: B21-B26

5. McGarry JD, Dobbins RL, (1999) Fatty acids, lipotoxicity and insulin secretion. Diabetologia 42: 128-138

6. Crespin SR, Greenough WB, Steinberg D (1973) Stimulation of insulin secretion by long-chain free fatty acids. A direct pancreatic effect. J Clin Invest 52: 1979-1984
7. Balasse EO, Ooms HA (1973) Role of plasma free fatty acids in the control of insulin secretion in man. Diabetologia 9: $145-151$

8. Chalkley SM, Kraegen EW, Furler SM, Campbell LV, Chisholm DJ (1998) NEFA elevation during a hyperglycaemic clamp enhances insulin secretion. Diabet Med 15: 327-333

9. Carpentier A, Mittelman SD, Lamarche B, Bergman RN, Giacca A, Lewis GF (1999) Acute enhancement of insulin secretion by FFA in humans is lost with prolonged FFA elevation. Am J Physiol 276: E1055-E1066

10. Boden G, Chen X, Rosner J, Barton M (1995) Effects of a 48-h fat infusion on insulin secretion and glucose utilization. Diabetes 44: 1239-1242

11. Carpentier A, Mittelman SD, Bergman RN, Giacca A, Lewis GF (2000) Prolonged elevation of plasma free fatty acids impairs pancreatic $\beta$-cell function in obese nondiabetic humans but not in individuals with Type 2 diabetes. Diabetes 49: 399-408

12. Paolisso G, Gambardella A, Amato L et al. (1996) Opposite effects of short- and long-term fatty acid infusion on insulin secretion in healthy subjects. Diabetologia 38: 1295-1299

13. Paolisso G, Tagliamonte MR, Rizzo MR et al. (1998) Lowering fatty acids potentiates acute insulin response in first degree relatives of people with Type II diabetes. Diabetologia 41: 1127-1132

14. Fasching P, Ratheiser K, Nowotny P, Uurzemann S, Parzer $\mathrm{S}$, Waldhausl W (1994) Insulin production following intravenous glucose, arginine, and valine: different pattern in patients with impaired glucose tolerance and non-insulindependent diabetes mellitus. Metabolism 43: 385-389

15. Dobbins RL, Chester MW, Stevenson BE, Daniels MB, Stein DT, McGarry JD (1998) A fatty acid- dependent step is critically important for both glucose- and non-glucose-stimulated insulin secretion. J Clin Invest 101: 2370-2376

16. Elks ML (1993) Chronic perifusion of rat islets with palmitate suppresses glucose-stimulated insulin release. Endocrinology 133: 208-214

17. Pareja A, Tinahones FJ, Soriguer FJ et al. (1997) Unsaturated fatty acids alter the insulin secretion response of the islets of Langerhans in vitro. Diabetes Res Clin Pract 38: 143-149

18. Zhou YP, Grill VE (1994) Long-term exposure of rat pancreatic islets to fatty acids inhibits glucose-induced insulin secretion and biosynthesis through a glucose fatty acid cycle. J Clin Invest 93: 870-876

19. Lameloise N, Muzzin P, Prentki M, Assimacopoulos-Jeannet $F$ (2001) Uncoupling protein 2: a possible link between fatty acid excess and impaired glucose-induced insulin secretion? Diabetes 50: 803-809

20. Fajans SS, Floyd JCJ, Knopf RF et al. (1967) A difference in mechanism by which leucine and other amino acids induce insulin release. J Clin Endocrinol Metab 27: 1600-1606

21. Fajans SS, Christensen HN, Floyd JCJ, Pek S (1974) Stimulation of insulin and glucagon release in the dog by a nonmetabolizable arginine analog. Endocrinology 94: 230-233

22. Smith PA, Sakura H, Coles B, Gummerson N, Proks P, Ashcroft FM (1997) Electrogenic arginine transport mediates stimulus-secretion coupling in mouse pancreatic betacells. J Physiol (Lond) 499: 625-635

23. Thams P, Capito K (1999) L-arginine stimulation of glucose-induced insulin secretion through membrane depolarization and independent of nitric oxide. Eur J Endocrinol 140: 87-93 
24. Lookene A, Skottova N, Olivecrona G (1994) Interactions of lipoprotein lipase with the active-site inhibitor tetrahydrolipstatin (Orlistat). Eur J Biochem 222: 395-403

25. Herman WH, Fajans SS, Smith MJ, Polonsky KS, Bell GI, Halter JB (1997) Diminished insulin and glucagon secretory responses to arginine in nondiabetic subjects with a mutation in the hepatocyte nuclear factor-4alpha/MODY1 gene. Diabetes 46: 1749-1754

26. Van Cauter E, Mestrez F, Sturis J, Polonsky KS (1992) Estimation of insulin secretion rates from C-peptide levels. Comparison of individual and standard kinetic parameters for C- peptide clearance. Diabetes 41: 368-377

27. Byrne MM, Sturis J, Menzel S et al. (1996) Altered insulin secretory responses to glucose in diabetic and nondiabetic subjects with mutations in the diabetes susceptibility gene MODY3 on chromosome 12. Diabetes 45: 1503-1510

28. Wiesenthal SR, Sandhu H, McCall RH et al. (1999) Free fatty acids impair hepatic insulin extraction in vivo. Diabetes 48: 766-774

29. Harding PE, Bloom G, Field JB (1975) Effect of infusion of insulin into portal vein on hepatic extraction of insulin in anesthetized dogs. Am J Physiol 228: 1580-1588

30. Ferrannini E, Wahren J, Faber OK, Felig P, Binder C, DeFronzo RA (1983) Splanchnic and renal metabolism of insulin in human subjects: a dose-response study. Am J Physiol 244: E517-E527

31. Morishima T, Bradshaw C, Radziuk J (1985) Measurement using tracers of steady-state turnover and metabolic clearance of insulin in dogs. Am J Physiol 248: E203-E208

32. Pye S, Watarai T, Davies G, Radziuk J (1993) Comparison of the continuously calculated fractional splanchnic extraction of insulin with its fractional disappearance using a new double-tracer technique. Metabolism 42: 145-153
33. Horwitz DL, Starr JI, Mako ME, Blackard WG, Rubenstein AH (1975) Proinsulin, insulin, and C-peptide concentrations in human portal and peripheral blood. J Clin Invest 55: $1278-1283$

34. Kahn SE, Beard JC, Schwartz MW et al. (1989) Increased beta-cell secretory capacity as mechanism for islet adaptation to nicotinic acid-induced insulin resistance. Diabetes 38: $562-568$

35. Weyer C, Bogardus C, Mott,DM, Pratley RE (1999) The natural history of insulin secretory dysfunction and insulin resistance in the pathogenesis of type 2 diabetes mellitus. J Clin Invest 104: 787-794

36. Mittelman SD, Van Citters GW, Kim SP et al. (2000) Longitudinal compensation for fat-induced insulin resistance includes reduced insulin clearance and enhanced beta-cell response. Diabetes 49: 2116-2125

37. Steil GM, Trivedi N, Jonas JC et al. (2001) Adaptation of beta-cell mass to substrate oversupply: enhanced function with normal gene expression. Am. J. Physiol 280: E788E796

38. Bergman RN, Phillips LS, Cobelli C (1981) Physiologic evaluation of factors controlling glucose tolerance in man. Measurement of insulin sensitivity and $\beta$-cell glucose sensitivity from the response to intravenous glucose. J Clin Invest 68: 1456-1467

39. Kahn SE, Prigeon RL, McCulloch DK et al. (1993) Quantification of the relationship between insulin sensitivity and $\beta$-cell function in human subjects. Evidence for a hyperbolic function. Diabetes 42: 1663-1672

40. Weinhaus AJ, Poronnik P, Tuch BE, Cook DI (1997) Mechanisms of arginine-induced increase in cytosolic calcium concentration in the beta-cell line NIT-1. Diabetologia 40: 374-382 